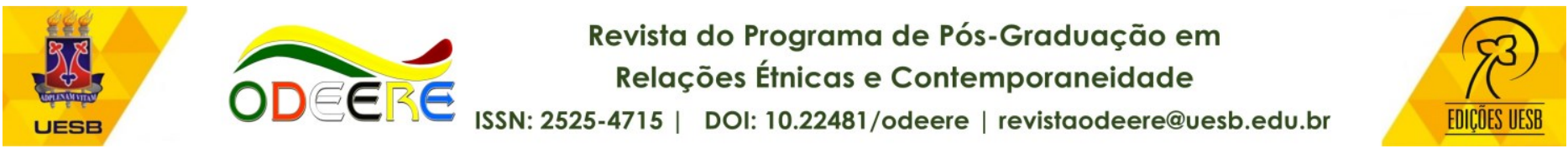

\title{
Madalena e Mirtes: "Por que as mulheres negras são as últimas da fila depois de ninguém?"
}

\author{
Marília do Amparo Alves Gomes 1 (iD) \\ Programa de Pós-Graduação em Educação (PPGED/UESB) \\ Tânia Rocha de Andrade Cunha ${ }^{2}$ iD \\ Universidade Estadual do Sudoeste da Bahia

\section{Dossiê | Dossier | Dosier \\ DOI do artigo: 10.22481/odeere.v6i01.8546} \\ RESUMO
}

Este artigo suscita uma reflexão sobre a condição que muitas mulheres negras ainda vivem na sociedade brasileira. Nesta breve análise examinamos as memórias coletivas dos grupos dominantes e dominados desde o contexto da escravidão brasileira até a sociedade atual tomando como base a teoria da memória de Maurice Halbwachs e Michael Pollak, recorremos também aos estudos de algumas feministas negras, a exemplo de Grada Kilomba, Bell Hooks, Sueli Carneiro e Chimamanda Adichie e também da feminista Heleieth Saffioti, que abordam o viés da interseccionalidade e escancara as desigualdades, opressões e violências enfrentadas pelas mulheres negras. Assim, a partir de uma análise qualitativa, podemos afirmar que: i) a memória coletiva de grupos da elite branca é memória oficial e reflete o modelo de relações raciais do Brasil; ii) a memória e o esquecimento marcam a trajetória do povo negro; iii) o projeto colonial se apresenta com novas roupagens do racismo.

Palavras-chave: Memória coletiva. Interseccionalidade. Escravidão. Mulheres negras.

\section{Madalena and Mirtes: "Why are black women the last in line after no one?" ABSTRACT}

This article raises a reflection on the condition that many black women still live in Brazilian society. In this brief analysis, we examine the collective memories of dominant and dominated groups from the context of Brazilian slavery to current society, taking as our basis the theoretical treatment of collective memory of Maurice Halbwachs and Michael Pollak, the studies of some black feminists, such as Grada Kilomba, Bell Hooks, Sueli Carneiro, and Chimamanda Adichie, who approach intersectionality and expose the inequalities, oppression, and violence faced by black women. Thus, from a qualitative analysis, we can state that: i) the collective memory of white elite groups is official memory and reflects the model of race relations in Brazil; ii) memory and forgetfulness mark the trajectory of black people; iii) the colonial project presents itself in new guises of racism.

Keywords: Collective memory. Intersectionality. Slavery. Black women.

\section{Submetido em: 29 de abr. de 2021 | Aceito em: 08 de jun. de 2021}

\footnotetext{
1 Assistente Social, Doutoranda em Memória, Linguagem e Sociedade (UESB); Mestra em Educação pela Universidade Estadual do Sudoeste da Bahia (UESB); Membro do Observatório de Mulheres negras OJU OBINRIN; Membro do Grupo de Pesquisa em Ludicidade, Didática e Práticas de Ensino (LUDIPE) e do Grupo de Estudos e Pesquisa em Políticas para a Educação Superior (GEPPES) da Universidade Estadual do Sudoeste da Bahia. Possui experiência como Analista Universitária na Universidade Estadual do Sudoeste da Bahia UESB compondo a Equipe Multidisciplinar do Programa de Assistência Estudantil. E-mail: mariliaamparo@gmail.com

2 Doutora em Ciências Sociais pela Pontifícia Universidade Católica (PUC) São Paulo. Docente do Programa de Pós-Graduação em Memória Linguagem e Sociedade da UESB. Mestra em Ciências Sociais pela PUC São Paulo. E-mail: tania.rochandrade@gmail.com
} 
Gomes, M. A. A., Cunha, T. R. A., Madalena e Mirtes: "Por que as mulheres negras são as últimas da

\section{INTRODUÇÃO}

Neste artigo, optamos por escrever a terceira pessoa na nossa escrita, para nos afirmar como vozes femininas que ocupam esse lugar da academia, que não apenas reproduz, mas também contribui com a construção do conhecimento. Do mesmo modo, para embasamento teórico recorremos a autoras feministas negras, com o objetivo de dar visibilidade às suas vozes. Sueli Carneiro enfatiza que na sociedade brasileira "as mulheres negras são as últimas da fila depois de ninguém"3, tamanha é a opressão e exclusão. Sendo assim, apresentamos as histórias de duas mulheres negras, com repercussão nacional, que nos ajudam a pensar a simultaneidade das opressões de raça, classe e gênero no Brasil.

A mídia impressa e televisiva noticiou em dezembro de 2020 a história de Madalena Gordiano 4 , mulher negra, de 46 anos, que desde os 8 anos de idade era explorada como empregada doméstica, sem recebimento de salário, em um trabalho análogo ao de escrava, em Patos - Minas Gerais. Madalena vivia em reclusão em um apartamento há 38 anos e era impedida até mesmo de andar ao ar livre. Esta situação só foi descoberta após denúncia feita ao Ministério Público do Trabalho.

Outro caso que também veio a público foi o de Mirtes Souza ${ }^{5}$, mulher negra, empregada doméstica, que assim como muitas outras mulheres nessa condição,

\footnotetext{
${ }^{3}$ CARNEIRO, Sueli. Racismo, sexismo e desigualdade no Brasil. Selo Negro. São Paulo. 2011.

${ }^{4} \mathrm{O}$ caso Madalena Gordiano foi noticiado pela mídia nacional e internacional, como rede globo de televisão,Mulher é libertada em MG após 38 anos vivendo em condições análogas à escravidão LFantástico | Gl (globo.com) e também Jornal El País: Caso de Madalena, escrava desde os oito anos, expõe legado vivo da escravidão no Brasil | Internacional | EL PAís Brasil (elpais.com)

${ }^{5}$ Mirtes Souza ficou conhecida pela sua luta por justiça, após a morte de seu filho Miguel Otávio, noticiado em toda mídia nacional Caso Miguel: como foi a morte do menino que caiu do $9^{\circ}$ andar de prédio no Recife | Pernambuco | Gl (globo.com); Mirtes atualmente é estudante de Direito Após perda do filho, mãe de Miguel se matricula em curso de direito (correiobraziliense.com.br)
} 
Gomes, M. A. A., Cunha, T. R. A., Madalena e Mirtes: "Por que as mulheres negras são as últimas da

se viu obrigada a levar seu filho Miguel Otávio, de cinco anos de idade, para o emprego, pois permaneceu trabalhando, mesmo no período de pandemia de Coronavírus. Em 02 de junho de 2020, seguindo a rotina do seu trabalho, Mirtes foi passear com os cães da família, deixando seu filho aos cuidados da sua patroa, Sari Corte Real, que de maneira negligente o deixou sair sozinho do apartamento e acessar o elevador do edifício de luxo que mora em Recife, do qual a criança acabou caindo do nono andar e faleceu.

As histórias de Madalena e Mirtes representam a condição das mulheres negras e nos levam a questionar: como as ações de grupos da elite branca brasileira materializam a memória coletiva sobre os negros e negras ao longo do tempo, da colônia aos dias atuais? As experiências dessas mulheres evidenciam a continuidade do projeto colonial que se reveste de novas estratégias?

Para tratar das atuais condições de vida da população negra é importante falar da memória da Escravidão, a qual tem sido objeto de estudo nos círculos acadêmicos e de debates entre o público em geral, tornando-se, muitas vezes, tema central de trabalhos como o de Andreta 6 que discute a voz e a memória de escravos a partir da literatura; o de Araújo7 $^{7}$ que investiga as diferentes representações da escravidão e do tráfico atlântico; e o de Rezende8 (2017) que analisa a memória da escravidão recriada na figura umbandista dos pretos-velhos. Além disso, destacamos o importante trabalho da intelectual negra Grada

\footnotetext{
${ }^{6}$ ANDRETA, Bárbara Loureiro; ALÓs, Anselmo Peres. A voz e a memória dos escravos: Úrsula, de Maria Firmina dos Reis. identidade! v. 18, n. 2, p. 194-200, 2014.

7 ARAÚJO, Ana Lucia. Caminhos atlânticos memória, patrimônio e representações da escravidão na Rota dos Escravos. Varia História, v. 25, n. 41, p. 129-148, 2009.

8REZENDE, LÍVIA LIMA. FORÇA AFRICANA, FORÇA DIVINA: a memória da escravidão recriada na figura umbandista dos pretos-velhos. São João del-Rei: UFSJ, 2017.
} 
Gomes, M. A. A., Cunha, T. R. A., Madalena e Mirtes: "Por que as mulheres negras são as últimas da

Kilomba9 que analisa os episódios de racismo cotidiano em Memórias de Plantação.

Neste sentido, estes estudos e reflexões demonstram a importância de preservar a memória, não para reforçar a imagem da comunidade negra como escravizada, mas para não esquecer da historicidade e das estratégias de resistência desse grupo.

Metodologicamente, foram escolhidos dois casos de repercussão, os quais tem como vítimas, mulheres negras em situação de opressão e violência. Selecionamos o G1 Portal de notícias da Globo e também o Correio Braziliense (CB), como espaços nos quais foram divulgadas as notícias. utilizamos como critérios, o acesso na modalidade online, alcance em todo território nacional e o fato de se constituírem há mais de quinze anos. Também recorremos a notícia divulgada no Jornal El País, jornal diário espanhol fundado em 1976, reconhecido mundialmente.

Nesta breve análise, abordamos a Memória a partir da teoria desenvolvida por Maurice Halbwachs e Michael Pollak, visando responder à nossa pergunta norteadora: Como podemos perceber a influência da memória coletiva de grupos da elite branca brasileira sobre a comunidade negra?

\footnotetext{
9 KILOMBA, Grada. Memórias da plantação: episódios de racismo cotidiano. Trad. Jess oliveira. 1. Ed. Rio de janeiro: cobogó, 2019.
} 


\section{A memória coletiva de grupos da elite branca brasileira sobre a comunidade negra}

A categoria memória coletiva foi criada por Maurice Halbwachs, que inaugurou os estudos sobre memória no campo das ciências sociais a partir dos estudos de Durkheim. Esse conceito leva em conta que a recordação e a localização das lembranças devem ser analisadas levando em consideração o contexto social, que é base para sua reconstrução, haja vista que as memórias de um sujeito não são apenas suas, as lembranças não existem isoladamente, estão ligadas a um grupo social, pois "cada memória individual é um ponto de vista sobre a memória coletiva", portanto, o indivíduo participa dos dois tipos de memória ${ }^{10}$

Halbwachs propõe o conceito como um modo de memória que se concretiza por meio da ação pública de grupos, dentro de quadros sociais específicos. A memória coletiva demonstra como determinado grupo é representante do passado, pois mesmo não tendo vivenciado, em muitos casos, associa as lembranças comuns a eventos históricos ou a um conjunto de eventos históricos.

Se tomarmos como exemplo a escravidão, a memória coletiva pode ser tanto a do grupo dominante que representa os escravocratas, quanto do grupo dominado, representada pelos escravizados. Nesse sentido, a diáspora africana ocasionada pelo sequestro de negros e negras gerou diversos traumas e diversos modos de lidar com a memória.

Portanto, é inegável a pluralidade das memórias do povo negro, uma vez

10 HALBWACHS, Maurice. A memória coletiva. Tradução de Beatriz Sidou. $2^{a}$ ed. São Paulo: Centauro, 2013. 
Gomes, M. A. A., Cunha, T. R. A., Madalena e Mirtes: "Por que as mulheres negras são as últimas da

que em cada país ou continente pode se apresentar de diferentes formas, já que essas memórias estão atreladas a diversos interesses na sociedade, a exemplo do Brasil, onde a elite branca é associada à elite escravocrata e continua como grupo dominante. Por outro lado, a população negra compõe a base da pirâmide social e ocupa os piores lugares nos indicadores sociais. Ainda que com exceções, ou seja, brancos em situação de pobreza e negros como parte da elite, as assimetrias raciais e sociais no Brasil são fortemente demarcadas.

Maurice Halbwachs, e posteriormente, também Michael Pollak, definem a memória como um fenômeno coletivo, ou seja, como uma construção social do passado realizada no presente. Os dois teóricos apontam o papel crucial da memória para a construção do sentimento de identidade. Deste modo, analisando a memória coletiva de grupos da elite branca acerca da população negra, percebemos certa homogeneidade com o modo de pensar atual, uma vez que esse pensamento que advém do período colonial, no qual os escravocratas exerciam o poder sobre os escravizados, se atualiza com as novas formas de escravização. Essa visão posiciona as pessoas negras em um lugar de subalternidade.

Ao encontro de tais reflexões vão as considerações de Michael Pollak, em seu ensaio Memória, Esquecimento, Silêncio'11 no qual dialoga com a obra de Maurice Halbwachs. O estudioso compreende a relação do homem com o passado em meio a conflitos entre a dimensão individual e a coletiva da memória,

11 POLLAK, Michael. Memória, esquecimento, silêncio. Revista estudos históricos, v. 2, n. 3, p. 3-15, 1989. 
Gomes, M. A. A., Cunha, T. R. A., Madalena e Mirtes: "Por que as mulheres negras são as últimas da

partilhando com Halbwachs, portanto, a observação de que a memória individual se produz na interação com o coletivo.

Em Halbwachs entendemos essa questão a partir das contribuições da memória para a formação de identidades, e isso ocorre porque os grupos se constituem como "comunidades de sentimentos". A adesão dos indivíduos aos grupos e às representações coletivas se dão no plano afetivo. Contudo, Pollak complementa o pensamento do seu mestre na discussão sobre coerção, e chama atenção para os processos de dominação que estão presentes na formação das memórias. O autor enxerga a homogeneidade de um grupo, como o desfecho da hegemonia. Se para Halbwachs a memória é múltipla, visto que cada grupo cultiva um conjunto particular de lembranças, para Pollak, essa diversidade é responsável por tornar a memória um objeto de conflitos e disputas, pois os grupos impõem suas visões acerca do passado sobre os demais, como é possível identificar na memória oficial sobre a escravidão, que tenta apagar as resistências da comunidade negra.

Na perspectiva de Halbwachs ${ }^{12}$ o passado é móvel, fluido, não é estanque, não se constitui em uma imagem. Neste sentido, podemos afirmar que as novas roupagens do racismo e as novas opressões impostas ao povo negro, guardam semelhanças com o período escravocrata, no qual era negada a condição humana à pessoa escravizada. Sueli Carneiro ${ }^{13}$ alerta sobre a necessidade de ampliação da luta pelos direitos humanos e o combate às desigualdades, à discriminação e à violência, situações presentes nas histórias de Madalena e Mirtes:

12 HALBWACHS, Maurice. A memória coletiva. Tradução de Beatriz Sidou. $2^{a}$ ed. São Paulo: Centauro, 2013.

${ }^{13}$ CARNEIRO, Sueli. Racismo, sexismo e desigualdade no Brasil. Selo Negro. São Paulo. 201 1, p. 15. 
Uma questão essencial acerca dos direitos humanos é a prevalência da concepção de que certos humanos são mais ou menos humanos do que outros, o que, consequentemente, leva à naturalização da desigualdade de direitos

Percebe-se que essa desumanização está atrelada à imagem da mulher negra. No caso de Madalena, a sua condição de empregada doméstica e sem direito à remuneração já representa uma forma grave de violência que desconsidera toda luta da classe trabalhadora para ter garantidos esses direitos. Somado a isso, a privação da liberdade, o enclausuramento e o impedimento de transitar nas ruas, traz à tona a ideia do poder e controle sobre o corpo negro como coisa ou mercadoria.

Diversos autores têm pesquisado sobre o surgimento do trabalho doméstico no Brasil, como resquícios do período da escravidão, quando eram selecionadas pessoas escravizados para trabalhar na "casa grande", em diversas atividades como cozinhar, arrumar, lavar, cuidar de crianças, dentre outras. Com a Lei Áurea, assinada pela Princesa Isabel em 13 de maio de 1888, e a abolição formal da escravatura, muitos escravos continuaram trabalhando na Casa Grande, obtendo em troca moradia e alimentação, haja vista que não dispunham de nenhuma outra alternativa para obter meios de sobrevivência. Foi necessária uma longa trajetória de lutas, para que esse grupo passasse a conquistar direitos trabalhistas ${ }^{14}$

Neste sentido, o mais expressivo avanço se dá com a Constituição Federal de 1988, especialmente no artigo $7^{\circ}$, com a igualdade de direitos entre trabalhadores urbanos, rurais, prevendo recebimento de Salário mínimo,

\footnotetext{
14 DAMACENO, Liliane Dias; CHAGAS, Sylvia Oliveira; CONTÁBEIS, Ciências. Evolução do direito trabalhista do empregado doméstico de 1916 a 2013-PEC das domésticas. Cadernos de Graduação-Ciências Humanas e Sociais| Aracaju| v, v. 1, n. 17, p. 63-76, 2013, p. 65.
} 
Gomes, M. A. A., Cunha, T. R. A., Madalena e Mirtes: "Por que as mulheres negras são as últimas da

irredutibilidade de salário em caráter absoluto; $13^{\circ}$ salário; repouso semanal remunerado, preferencialmente aos domingos; férias anuais remuneradas; licença gestante; licença paternidade; aviso prévio; e aposentadoria ${ }^{15}$

No ano de 2013, outra conquista importante foi a proposta de emenda constitucional número 72, conhecida como "PEC das domésticas", que incluiu novos direitos aos empregados domésticos, reconhecendo a exclusão desse grupo, historicamente explorado.

Muitos ex-escravos, agora denominados de empregados domésticos, por não terem para onde ir, ou o que fazer, permaneceram trabalhando para seus antigos senhores, em troca de abrigo e de comida, sendo tratados ora como serviçais, ora como familiares, numa forma de tão somente esconder as características de trabalho escravo que ainda eram inatos a esta classe ${ }^{16}$

Na realidade atual, podemos perceber, a partir da história de Madalena, os traços da relação entre Senhores e Escravos, e apesar dos avanços citados, ainda se mantém fortes traços de subordinação desse grupo que exerce o trabalho doméstico. A PEC das Domésticas, Emenda Constitucional n $72 / 13$, do artigo $7^{\circ}$ da Constituição Federal de 1988, garante a equiparação dos direitos trabalhistas entre os empregados domésticos e os demais trabalhadores rurais e urbanos, com garantia de Horas extras; Adicional pelo trabalho noturno; Salário-família; Auxílio creche e pré-escola para filhos e dependentes até 5 anos de idade; FGTS - Fundo de Garantia por Tempo de Serviço; Multa de $40 \%$ em caso de rescisão; Segurodesemprego; Seguro por acidente de trabalho; Adicional de periculosidade ou 15 BRASIL, Constituição Federal de 1988. Disponível em:
http://www.planalto.gov.br/ccivil 03/constituicao/constituicao.htm. Acessado em: 20/04/2021.
16 DAMACENO, Liliane Dias; CHAGAS, Sylvia Oliveira; CONTÁBEIS, Ciências. Evolução do direito
trabalhista do empregado doméstico de 1916 a 2013-PEC das domésticas. Cadernos de
Graduação-Ciências Humanas e Sociais | Aracaju/ v, v. 1, n. 17, p. 63-76, 2013, p. 65. 
Gomes, M. A. A., Cunha, T. R. A., Madalena e Mirtes: "Por que as mulheres negras são as últimas da

insalubridade 17

No entanto, na realidade concreta, nem sempre essas previsões são efetivadas. São recorrentes as denúncias de casos de violação dos direitos previstos nas legislações trabalhistas. Se essas situações já evidenciam o descaso e desprezo por esse grupo de trabalhadores, o que dizer das violências perpetradas contra as mulheres negras no trabalho análogo ao escravo?

Essa situação foi vivida por Madalena Gordiano por quase quatro décadas, com privação de liberdade, ausência de qualquer pagamento pelo exaustivo trabalho, alimentação insuficiente. Ela relata que a sua rotina de trabalho começava na madrugada, seguindo até a à noite e que os "patrões" tinham total controle sobre sua vida, impedindo-a de deixar o cabelo crescer, de estudar, de manter contato com outras pessoas. Em uma entrevista para o site (UOL) notícias, em 12 de janeiro de 2021, Madalena fala sobre um dos seus desejos realizados, logo após ter sido libertada, a compra de um vestido e de uma boneca ${ }^{18}$

Ângela Davis ${ }^{19}$ ao analisar as bases do sistema escravagista norteamericano enfatiza que negros e negras eram vistos apenas como unidades de trabalho lucrativo e não como seres humanos. Apesar das especificidades, podemos tomar a análise de Davis como base para compreender a realidade brasileira, haja vista que o nosso país também é herdeiro de uma estrutura

\footnotetext{
17 BRASIL. EMENDA CONSTITUCIONAL N 72, DE 2 DE ABRIL DE 2013. Altera a redação do parágrafo único do art. $7^{\circ}$ da Constituição Federal. Disponível em: http://www.planalto.gov.br/ccivil 03/constituicao/emendas/emc/emc72.htm>. Acessado em: 22/04/2021.

18 MADALENA Gordiano conta detalhes dos 38 anos de escravidão que viveu em MG. UOL ENTREVISTA. https://www.youtube.com/watch? v=uel qeBUq4gc>. Acessado em: 10/04/2021.
}

19DAVIS, Angela. Mulheres, raça e classe. São Paulo: Boitempo, 2016. 
escravista.

No caso de Mirtes, podemos observar a repetição da imagem da mulher negra e pobre que precisa sair para trabalhar, neste caso, também como empregada doméstica. O fato de ter que trabalhar e na ocasião não ter onde deixar o filho gerou uma situação na qual Ihe foi permitido levar a criança para o ambiente de trabalho. Como parte da sua rotina, Mirtes precisou sair para passear com o cachorro da família, momento no qual o filho Miguel ficou sob a responsabilidade da patroa. Como as opressões também atingem as crianças, o caso de Miguel ilustra a sua total desumanização. Procurando pela mãe, Miguel de apenas 5 anos acessa sozinho o elevador com a permissão da patroa. A total negligência da patroa naquele momento demonstra que aquela criança não foi tratada como merecedora de atenção e cuidado, diferente dos cães que a sua mãe levou para passear. Sari Corte, não demonstrou qualquer preocupação, tratando-a como uma pessoa responsável por seus atos, o que resultou na sua morte.

Diversos pesquisadores têm demonstrado a continuidade das opressões no período pós abolição, uma vez que não houve mudanças nas estruturas hierárquicas impostas pela lógica escravista. Na realidade social do pós-abolição, as mulheres que eram escravas tornaram-se empregadas domésticas, para elas a liberdade não se efetivou de fato. O trabalho doméstico é resquício escravocrata de cunho sexista, que atinge principalmente as mulheres negras inseridas em uma estrutura de opressão racista, classista e sexista que as mantém no lugar periférico 
Gomes, M. A. A., Cunha, T. R. A., Madalena e Mirtes: "Por que as mulheres negras são as últimas da fila depois de ninguém?". ODEERE, v. 6, n. 01, jan./jun., p. 84-108, 2021. https://doi.org/10.22481/odeere.v6i01.8546

e marginal20 e ${ }^{21}$ como é o caso Mirtes e Madalena.

Podemos perceber então, que determinadas ações de grupos da elite brasileira materializam a memória coletiva sobre os negros e negras ao longo do tempo e evidencia a construção do que Chimamanda Ngozi Adichie 22 chama de "o perigo de uma história única" pois "é assim que se cria uma história única: mostre um povo como uma coisa, uma coisa só, sem parar, e é isso que esse povo se torna". Assim, essa ideia do povo negro como coisa é contínua, mas, mesmo enfrentando essa realidade, podemos dizer, citando Foucault23 que um pluralismo de forças suscita um pluralismo de resistências.

\section{INTERSECCIONALIDADES: as diversas opressões que atingem simultaneamente as mulheres negras}

As discussões sobre interseccionalidade não são recentes. Ângela Davis24 já discutia este conceito, mesmo sem nomeá-lo, ao tratar das situações de desigualdades e opressões às quais as mulheres negras são submetidas historicamente. Com ênfase na forma pela qual as opressões de gênero, raça e classe se entrecruzam, a autora propõe como saída a construção de um projeto político comprometido com a liberdade.

\footnotetext{
20 DE PAULA PEREIRA, Bergman. De escravas a empregadas domésticas-A dimensão social e o" lugar" das mulheres negras no pós-abolição. Anais do Encontro da ANPUH, 2011.

${ }^{21} \mathrm{JOHN}$, Júlia Castro. MULHERES NEGRAS, A INTERSECCIONALIDADE DAS OPRESSÕES, O TRABALHO DOMÉSTICO E A LUTA POR DIREITOS. ENCRESPANDO Seminário Internacional, v. 1, n. 1, 2015.

${ }^{22} \mathrm{ADICHIE}$, Chimamanda Ngozi. O perigo de uma história única. São Paulo: Companhia das Letras, 2019.

${ }^{23}$ FOUCAULT, Michel. Genealogia do Poder in: Microfísica do Poder. Rio de Janeiro: Edições Graal, 1979a e 1981.

24 DAVIS, Angela. Mulheres, raça e classe. São Paulo: Boitempo, 2016.
} 
Gomes, M. A. A., Cunha, T. R. A., Madalena e Mirtes: "Por que as mulheres negras são as últimas da

Com o conceito de interseccionalidade há o reconhecimento de que não existe hierarquia de opressões, ou seja, o sexismo, o racismo e a opressão de classe atingem de forma simultânea, sendo deste modo, impossível categorizá-las em uma escala de opressões. Os estudos na perspectiva Interseccional evidenciam que essa simultaneidade das opressões produz experiências específicas de violência. A feminista e jurista Kimberlé Crenshaw25 cunhou esse conceito e o utilizou pela primeira vez nos anos de 1980, para lidar com as desigualdades norte americanas, afirmando que a interseccionalidade trata "da forma pela qual o racismo, o patriarcalismo, a opressão de classe e outros sistemas discriminatórios criam desigualdades básicas que estruturam as posições relativas de mulheres, raças, etnias, e classes", portanto, uma análise sob essas lentes possibilita a compreensão da situação das mulheres negras no Brasil.

A escolha de um direcionamento da análise para esse grupo, justifica-se a partir de duas questões centrais: primeira, devido ao passado colonial, no qual o sequestro e a escravização do povo negro tiveram como principais vítimas as mulheres negras, com repercussões até os dias atuais, como demonstram os indicadores sociais; segunda, porque os grupos historicamente oprimidos, neste caso as mulheres e a população negra, passaram a se organizar para reivindicar mudanças e direitos que lhes foram negados, no entanto, a mulher negra não vê suas dores específicas representadas em nenhum desses grupos, pois percebe-se a presença de "um debate sobre racismo no qual o sujeito é o homem negro; um discurso genderizado no qual o sujeito é a mulher branca; e um discurso de classe

${ }^{25}$ CRENSHAW, Kimberlé. Background paper for the expert meeting on the gender- related aspects of race discrimination. Estudos Feministas, v. 10, n. 1, p. 171, 2002, p. 170. 
Gomes, M. A. A., Cunha, T. R. A., Madalena e Mirtes: "Por que as mulheres negras são as últimas da

no qual "raça" não tem nem lugar", então é necessário uma lente específica para descortinar as opressões sofridas pelas mulheres negras 26

Saffioti27 ao discutir sobre a relação gênero, raça/etnia e poder, chama atenção para o fenômeno da solidão da mulher negra, uma vez que

a resposta de homens negros ao racismo, mormente dos que conquistaram uma posição social e/ov econômica privilegiada, foi o casamento com mulheres loiras. Se eles são socialmente inferiores a elas em razão da cor de sua pele e da textura de seus cabelos, elas são inferiores a eles na ordem patriarcal de gênero.

Portanto, ainda conforme a autora, os homens negros com poder aquisitivo de um lado, e as mulheres brancas que sofrem com o sexismo, buscam equalizar as discriminações sofridas, todavia, quando se trata das mulheres negras, não é possivel estabelecer tal igualdade com os homens brancos, pois "estes são "superiores" pela cor de sua pele e pela textura de seus cabelos, sendo "superiores" também em razão de seu sexo. Na ordem patriarcal de gênero, o branco encontra sua segunda vantagem, percebemos então o lugar da mulher negra nessa pirâmide 28

Deste modo, a Interseccionalidade é uma categoria teórica que apresenta como foco, os múltiplos sistemas de opressão, especialmente raça, gênero e classe. A feminista negra Carla Akotirene, alerta que esse conceito "demarca o paradigma teórico e metodológico da tradição feminista negra, promovendo intervenções políticas e letramentos jurídicos sobre quais condições estruturais o

\footnotetext{
26 KILOMBA, Grada. Memórias da plantação: episódios de racismo cotidiano. Trad. Jess oliveira. 1. Ed. Rio de janeiro: cobogó, 2019, p. 97.

27 SAFFIOTI, Heleieth lara Bongiovani. Gênero, patriarcado, violência. São Paulo: Editora Fundação Perseu Abramo, 2015, p. 32.

28 SAFFIOTI, Heleieth lara Bongiovani. Gênero, patriarcado, violência. São Paulo: Editora Fundação Perseu Abramo, 2015, p. 32.
} 
Gomes, M. A. A., Cunha, T. R. A., Madalena e Mirtes: "Por que as mulheres negras são as últimas da fila depois de ninguém?". ODEERE, v. 6, n. 01, jan./jun., p. 84-108, 2021. https://doi.org/10.22481/odeere.v6i01.8546

racismo, o sexismo e as violências correlatas se sobrepõem, discriminam e criam encargos singulares às mulheres negras.", Podemos considerar assim, a interseccionalidade como uma categoria de análise importante para pensarmos as desigualdades no contexto brasileiro ${ }^{29}$

É possível perceber a materialização dessas desigualdades nos dados estatísticos. De acordo com a pesquisa publicada pelo IBGE, denominada "Desigualdade social por cor ou raça no Brasil", que tem como ano de referência 2019, as mulheres negras ganham em média menos da metade dos salários dos homens, totalizando $44,4 \%$. Esse dado demonstra as assimetrias raciais e sociais no Brasil. É inegável que esse grupo é o que mais sofre com o sistema de exploração e opressão ${ }^{30}$

Se falarmos de violência, perceberemos também que as mulheres negras são as maiores vítimas. O Instituto de Pesquisa Econômica Aplicada (IPEA) divulgou em 2020, O Atlas da Violência31, que revelou números alarmantes, em 2018, 4.519 mulheres foram assassinadas no Brasil, o que significa uma taxa de 4,3 homicídios para cada 100 mil habitantes do sexo feminino. Destaca-se como avanço, a redução da taxa de homicídios contra mulheres entre 2017 e 2018.

Contudo, somente no ano de 2018, a cada duas horas, uma mulher foi assassinada no Brasil, totalizando 4.519 vítimas. Diante desse cenário, o que chama

\footnotetext{
29 AKOTIRENE, Carla. Interseccionalidade. São Paulo: Pólen Livros, 2019. 152 p.

30 INSTITUTO BRASILEIRO DE GEOGRAFIA E ESTATÍSTICA. Desigualdades sociais por cor ou raça no Brasil. Estudos e Pesquisas-Informação Demográfica e Socioeconômica, v. 41, 2019. Disponível em:<liv101681_informativo.pdf (ibge.gov.br)>. Acessado em: 03/03/2021.

31 IPEA. Atlas da Violência 2020. Brasília / Rio de Janeiro / São Paulo: Instituto de Pesquisa Econômica Aplicada; Fórum Brasileiro de Segurança Pública, 2019. Disponível em:https://www.ipea.gov.br/atlasviolencia/download/24/atlas-da-violencia-2020. Acessado em: 30/02/202.
} 
Gomes, M. A. A., Cunha, T. R. A., Madalena e Mirtes: "Por que as mulheres negras são as últimas da

atenção é o fato de que apesar da redução de 8,4\% entre 2017 e 2018, no número de homicídios femininos, uma análise da última década, revela que a situação melhorou apenas para as mulheres não negras, confirmando as assimetrias raciais. Enquanto entre 2017 e 2018, houve uma queda de 12,3\% nos homicídios de mulheres não negras, entre as mulheres negras essa redução foi de $7,2 \%$. Com dados ainda mais assustadores, a análise do período entre 2008 e 2018 revela que enquanto a taxa de homicídios de mulheres não negras caiu $11,7 \%$, a taxa entre as mulheres negras aumentou $12,4 \%$.

A partir desses dados é possível inferir que o fenômeno da violência contra as mulheres é uma realidade no contexto brasileiro e carece cada vez mais de políticas que combatam e previnam; outra questão evidenciada pelos dados é a necessidade de um olhar mais aguçado para um grupo específico que é atingido de forma mais exacerbada, as mulheres negras.

Podemos ampliar o conceito, para compreender que as mulheres negras são atingidas por violências interseccionais, as quais muitas vezes estão invisibilizadas, inclusive nesses números, pois nem sempre são alcançadas pelo sistema de justiça. Nos estudos sobre violência contra mulheres é importante a abordagem gênero, mas também considerar a interseccionalidade entre este e outros marcadores, como raça e classe.

As histórias de Madalena e Mirtes, mulheres negras, empregadas domésticas, ilustram as violências interseccionais cometidas historicamente contra esse grupo, e mostram a atualização dos aspectos de opressão da Colônia para os dias atuais. A memória da escravidão revela que as mulheres negras eram vistas 
Gomes, M. A. A., Cunha, T. R. A., Madalena e Mirtes: "Por que as mulheres negras são as últimas da

como submissas, mercadorias, prontas para servir incansavelmente. A imagem de Mirtes, passeando com os cães e para tanto, deixando o filho aos cuidados da patroa, que o negligenciou, nos lembra cenas da Casa Grande, nas quais era negada às crianças negras escravizadas a convivência com suas mães, muitas eram obrigadas a tornarem-se amas de leite, amamentando os filhos dos senhores, em detrimento do próprio filho. Com as novas roupagens do racismo, a criança negra vem depois dos animais, na escala de prioridades.

Do mesmo modo, Madalena é literalmente escravizada em pleno século XXI, no mesmo modelo colonial, o corpo negro sem alimentação adequada, coisificado, aprisionado, desumanizado. Ela foi escravizada desde os 08 anos de idade, quando foi pedir pão em uma casa. Assim como nas relações entre senhores e escravos, Madalena foi cedida a outro filho da família, o professor de veterinária Dalton Milagres Rigueira. Em ambos os casos, é notório o legado vivo da escravidão.

Isso nos lembra o célebre discurso de Sojourner Truth, intitulado Não sou uma mulher? proferido em 1851, na Convenção dos Direitos da Mulher em Akron, Ohio, no qual ela questionava se por ser negra, não era mulher. Isto porque, às mulheres negras sempre foram impostos trabalhos que exigiam a mesma força física dos homens. Num dos trechos de seu discurso, divulgado no site eletrônico Portal Geledés em 08 de janeiro de 2014, Truth afirma: “(...) eu poderia trabalhar tanto e comer tanto quanto qualquer homem - desde que eu tivesse oportunidade para isso - e suportar o açoite também! Não sou uma mulher? (...)". Sojourner Truth alerta que as mulheres negras nunca foram tratadas como frágeis, ao contrário disso, seus 
Gomes, M. A. A., Cunha, T. R. A., Madalena e Mirtes: "Por que as mulheres negras são as últimas da

corpos sempre foram vistos como incansáveis para o trabalho32

No cenário brasileiro, a escravidão deixa também como legado, resistências, mesmo sendo silenciadas na Memória oficial. Sobre essa questão, Sueli Carneiro nos convida a pensar a contribuição do feminismo negro na luta antirracista. Esse movimento escancarou as implicações do racismo e do sexismo que oprimem as mulheres negras, e destaca que tais implicações ao mesmo tempo que lançam as vítimas nos piores indicadores sociais, engendram estratégias de resistência e superação:

O efervescente protagonismo das mulheres negras, orientado num primeiro momento pelo desejo de liberdade, pelo resgate de humanidade negada pela escravidão e, num segundo momento, pontuado pelas emergências das organizações de mulheres negras e articulações nacionais de mulheres negras, vem desenhando novos cenários e perspectivas para as mulheres negras e recobrindo as perdas históricas ${ }^{33}$

Então, no contexto macro, o feminismo negro reconhece os avanços obtidos por meio do movimento feminista, como o confronto ao sexismo internalizado, ideia de sororidade como algo poderoso, que segundo Bell Hooks cria uma base para a solidariedade entre as mulheres, a "sororidade feminista está fundamentada no comprometimento compartilhado de lutar contra a injustiça patriarcal, não importa a forma que a injustiça toma", além disso, o reconhecimento da importância dos homens como aliados na luta contra o sexismo e o patriarcalismo. É inegável também as outras pautas do movimento

32 TRUTH, Sojouner. E não sou eu uma mulher? Convenção pelos Direitos das Mulheres. Portal GELEDÉS. 08 de jan. 2014.Disponível em:<E não sou uma mulher? - SojournerTruth - Geledés (geledes.org.br)>. Acessado em: 20/02/2021.

${ }^{33}$ CARNEIRO, Sueli. Mulheres em movimento. Estudos avançados, v. 17, n. 49, p. 117-133, 2003, p. 129. 
Gomes, M. A. A., Cunha, T. R. A., Madalena e Mirtes: "Por que as mulheres negras são as últimas da

feminista, como a luta pelos direitos reprodutivos, a inserção da discussão de classe, reconhecendo a maior vulnerabilidade das mulheres em situação de pobreza; o combate à violência contra as mulheres. Contudo, Bell Hooks alerta que a sororidade feminista só se efetivará de fato, quando as mulheres deixarem de usar o poder de classe e de raça para dominar outras mulheres ${ }^{34}$

O feminismo negro, como um movimento teórico, político, social e prático, tem como base as pautas das mulheres negras e suas experiências na diáspora africana. Para o feminismo negro a situação de exclusão e desigualdades desse grupo é resultado da intersecção de opressões de gênero e de raça, além de outros marcadores, portanto, retirar essa mulher negra da base da pirâmide social é mexer com toda estrutura de opressão ${ }^{35}$

Do mesmo modo, o feminismo negro no Brasil, analisa a realidade interna, chamando atenção para a dimensão estrutural do racismo. Uma das maiores expoentes do movimento, a filósofa Sueli Carneiro ${ }^{36}$ chama atenção para a desigualdade no país. No que concerne à questão específica da Mulher negra, Carneiro afirma que estas sofrem uma espécie de asfixia social, que repercutem negativamente em várias dimensões da vida e tem como consequências: "danos à saúde mental e rebaixamento da autoestima, expectativa menor em cinco anos em relação às mulheres brancas; em um menor índice de casamentos; e sobretudo, no confinamento nas ocupações de menor prestígio e remuneração", apesar disso, ainda segundo a autora, com a maior compreensão do impacto do

\footnotetext{
34 HOOKS, Bell. O feminismo é para todo mundo: políticas arrebatadoras. Rio de Janeiro: Rosa dos Tempos, 2018, p. 36

${ }^{35}$ DAVIS, Angela. Mulheres, raça e classe. São Paulo: Boitempo, 2016.

${ }^{36}$ CARNEIRO, Sueli. Racismo, sexismo e desigualdade no Brasil. Selo Negro. São Paulo. 2011, p. 128.
} 
Gomes, M. A. A., Cunha, T. R. A., Madalena e Mirtes: "Por que as mulheres negras são as últimas da

binômio racismo/sexismo percebe-se maior solidariedade entre mulheres.

Com o objetivo de dar visibilidade a importância do pensamento feminista negro, enumeramos algumas conquistas, que foram alcançadas a partir das lutas de mulheres negras, que sempre tiveram na composição, e muitas vezes na liderança do movimento negro, a exemplo da implementação de políticas de ações afirmativas, como: obrigatoriedade do ensino da história da África, da educação das relações raciais e da cultura afro-brasileira; implementação da lei Afonso Arinos (Lei n. ${ }^{\circ} .390 / 1951$ ), com a concessão de titulação de quilombos; cotas raciais para ingresso em Universidades e concursos públicos, entre outras ações, que se configuram como verdadeiros avanços.

Sueli Carneiro ${ }^{37}$ corrobora com essa discussão, chamando atenção para a necessidade de maior investimento estatal em políticas específicas para esse segmento, que sejam capazes de reduzir as desigualdades entre negros e brancos.

\section{CONSIDERAÇÕES FINAIS}

Neste artigo apresentamos uma breve análise sobre a memória coletiva e a interseccionalidade, com ênfase nas opressões que historicamente atingem as mulheres negras, no contexto brasileiro. Para isso, inicialmente recorremos à discussão sobre Memória a partir da teoria de Maurice Halbwachs e Michael Pollak, demonstrando que os grupos dominantes fazem reverberar sua memória sobre a escravidão, reinventando novas formas de opressão. Como resultados dessa breve análise, identificamos que a memória coletiva de grupos da elite branca reflete o

${ }^{37}$ CARNEIRO, Sueli. Racismo, sexismo e desigualdade no Brasil. Selo Negro. São Paulo. 2011. 
Gomes, M. A. A., Cunha, T. R. A., Madalena e Mirtes: "Por que as mulheres negras são as últimas da

modelo de relações raciais atuais do Brasil; a trajetória do povo negro no Brasil é marcada por opressões, mas também por resistências; as lentes da interseccionalidade ajudam a compreender as desigualdades e as possibilidades de enfrentamento.

Finalmente, é com base no pensamento feminista negro, que reforçamos o convite de Chimamanda Ngozi Adichie ${ }^{38}$ de rejeitarmos a história única, para percebermos que "nunca existe uma história única sobre lugar nenhum". Quando entendemos isso, "reavemos uma espécie de paraíso", por isso a necessidade de dar visibilidade à voz e às experiências das mulheres negras. Com o intuito de ilustrar essas experiências, apresentamos as histórias de Madalena e Mirtes (mãe de Miguel), demonstrando a persistência das opressões de classe, raça e gênero, que atingem as mulheres e crianças negras frontalmente, com o ápice nas diversas formas de extermínio dos seus corpos.

\section{REFERÊNCIAS}

ADICHIE, Chimamanda Ngozi. O perigo de uma história única. São Paulo: Companhia das Letras, 2019.

ANDRETA, Bárbara Loureiro; ALÓS, Anselmo Peres. A voz e a memória dos escravos: Úrsula, de Maria Firmina dos Reis. identidade! v. 18, n. 2, p. 194-200, 2014.

ARAÚJO, Ana Lucia. Caminhos atlânticos memória, patrimônio e representações

$38 \mathrm{ADICHIE}$, Chimamanda Ngozi. O perigo de uma história única. São Paulo: Companhia das Letras, 2019, p. 33 
Gomes, M. A. A., Cunha, T. R. A., Madalena e Mirtes: "Por que as mulheres negras são as últimas da fila depois de ninguém?". ODEERE, v. 6, n. 01, jan./jun., p. 84-108, 2021. https://doi.org/10.22481/odeere.v6i01.8546

da escravidão na Rota dos Escravos. Varia História, v. 25, n. 41, p. 129-148, 2009.

BRASIL, Constituição Federal de 1988. Disponível em: http://www.planalto.gov.br/ccivil_03/constituicao/constituicao.htm. Acessado em: 20/04/2021.

CARNEIRO, Sueli. Mulheres em movimento. Estudos avançados, v. 17, n. 49, p. $117-$ 133, 2003.

CARNEIRO, Sueli. Racismo, sexismo e desigualdade no Brasil. Selo Negro. São Paulo. 2011.

CRENSHAW, Kimberlé. Background paper for the expert meeting on the genderrelated aspects of race discrimination. Estudos Feministas, v. 10, n. 1, p. 171, 2002.

DAMACENO, Liliane Dias; CHAGAS, Sylvia Oliveira; CONTÁBEIS, Ciências. Evolução do direito trabalhista do empregado doméstico de 1916 a 2013-PEC das domésticas. Cadernos de Graduação-Ciências Humanas e Sociais| Aracaju| v, v. 1, n. 17, p. 63-76, 2013.

DAVIS, Angela. Mulheres, raça e classe. São Paulo: Boitempo, 2016

DE PAULA PEREIRA, Bergman. De escravas a empregadas domésticas-A dimensão social e o" lugar" das mulheres negras no pós-abolição. Anais do Encontro da ANPUH, 2011.

FOUCAULT, Michel. Genealogia do Poder in: Microfísica do Poder. Rio de Janeiro: Edições Graal, 1979a e 1981. 
Gomes, M. A. A., Cunha, T. R. A., Madalena e Mirtes: "Por que as mulheres negras são as últimas da fila depois de ninguém?". ODEERE, v. 6, n. 01, jan./jun., p. 84-108, 2021. https://doi.org/10.22481/odeere.v6i01.8546

HALBWACHS, Maurice. A memória coletiva. Tradução de Beatriz Sidou. $2^{a}$ ed. São Paulo: Centauro, 2013.

HOOKS, Bell. O feminismo é para todo mundo: políticas arrebatadoras. Rio de Janeiro: Rosa dos Tempos, 2018.

INSTITUTO BRASILEIRO DE GEOGRAFIA E ESTATÍSTICA. Desigualdades sociais por cor ou raça no Brasil. Estudos e Pesquisas-Informação Demográfica e Socioeconômica, v. 41, 2019. Disponível em: $<$ liv101681 informativo.pdf (ibge.gov.br)>. Acessado em: $03 / 03 / 2021$.

IPEA. Atlas da Violência 2020. Brasília / Rio de Janeiro / São Paulo: Instituto de Pesquisa Econômica Aplicada; Fórum Brasileiro de Segurança Pública, 2019. Disponível em:https://www.ipea.gov.br/atlasviolencia/download/24/atlas-daviolencia-2020. Acessado em: 30/02/2021.

JOHN, Júlia Castro. MULHERES NEGRAS, A INTERSECCIONALIDADE DAS OPRESSÕES, O TRABALHO DOMÉSTICO E A LUTA POR DIREITOS. ENCRESPANDO Seminário Internacional, v. 1, n. 1, 2015.

KILOMBA, Grada. Memórias da plantação: episódios de racismo cotidiano. Trad. Jess oliveira. 1. Ed. Rio de janeiro: cobogó, 2019.1

MADALENA Gordiano conta detalhes dos 38 anos de escravidão que viveu em MG. UOL ENTREVISTA. https://www.youtube.com/watch?v=uelqeBUq4gc>. Acessado em: 10/04/2021. 
Gomes, M. A. A., Cunha, T. R. A., Madalena e Mirtes: "Por que as mulheres negras são as últimas da fila depois de ninguém?". ODEERE, v. 6, n. 01, jan./jun., p. 84-108, 2021. https://doi.org/10.22481/odeere.v6i01.8546

MULHER é libertada em MG após 38 anos vivendo em condições análogas à escravidão. G1 notícias. 20 de dez. 2020. Disponível em: <é libertada em MG após 38 anos vivendo em condições análogas à escravidão $\mid$ Fantástico | Gl (globo.com)>. Acessado em: 03/03/2021.

POLLAK, Michael. Memória, esquecimento, silêncio. Revista estudos históricos, v. 2 , n. 3, p. 3-15, 1989.

REZENDE, LÍVIA LIMA. FORÇA AFRICANA, FORÇA DIVINA: a memória da escravidão recriada na figura umbandista dos pretos-velhos. São João del-Rei: UFSJ, 2017.

SAFFIOTI, Heleieth lara Bongiovani. Gênero, patriarcado, violência. São Paulo: Editora Fundação Perseu Abramo, 2015.

TRUTH, Sojouner. E não sou eu uma mulher? Convenção pelos Direitos das Mulheres. Portal GelEDÉS. 08 de jan. 2014.Disponível em: <E não sou uma mulher? SojournerTruth - Geledés (geledes.org.br)>. Acessado em: 20/02/2021. 
Gomes, M. A. A., Cunha, T. R. A., Madalena e Mirtes: "Por que as mulheres negras são as últimas da fila depois de ninguém?". ODEERE, v. 6, n. 01, jan./jun., p. 84-108, 2021. https://doi.org/10.22481/odeere.v6i01.8546

(c)

This work is licensed under a Licence Creative Commons Attribution 4.0 International License.

cc)

Este trabalho está licenciado com uma Licença Creative Commons - Atribuição 4.0

Internacional. 